\title{
Extreme coronary artery tortuosity in association with tortuosity of the systemic arteries: a rare and challenging situation for the interventionist
}

\author{
Pritesh Parekh, Navin Agrawal, Apurva Vasavada, Mahesh Vinchurkar
}

Department of Cardiovascular Sciences Care Hospital, Surat, Gujarat, India

\section{Correspondence to} Dr Navin Agrawal, drnavinagrawal@gmail.com

Accepted 8 May 2014
CrossMark

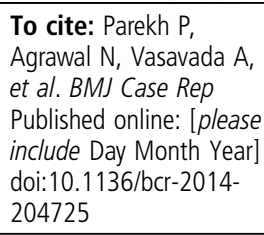

\section{DESCRIPTION}

Coronary tortuosity is conventionally defined as two or more consecutive $180^{\circ}$ turns in a major epicardial artery assessed by visual estimation. It is a relatively uncommon finding during diagnostic angiograms and the presence of multiple tortuous segments is very rare and presents an interesting angiographic image. ${ }^{1}$

We present an interesting angiographic image of an incidentally detected excessive coronary artery tortuosity in a middle-aged woman who presented to us for a diagnostic angiogram for the evaluation of atypical chest pain. The exercise ECG stress test was positive for inducible ischaemia. The patient was taken up for angiogram from the right radial route. Despite repeated attempts by experienced interventionists, we were unable to pass the sheath guide wire through the right as well as the left radial artery due to extreme tortuosity in the radial artery of both hands. The diagnostic angiogram subsequently performed from the right femoral arterial access revealed extreme tortuosity involving all the three coronary arteries with no flow-limiting lesion (figures 1-4, videos 1-4).

The patient was planned for conservative treatment directed at the management of microvascular disease and coronary artery spasm, which could have been the cause of chest pain in this patient.

The pathophysiological mechanism of coronary tortuosity is not clear. Traction and pressure in the lumen are known to lengthen a vessel and these

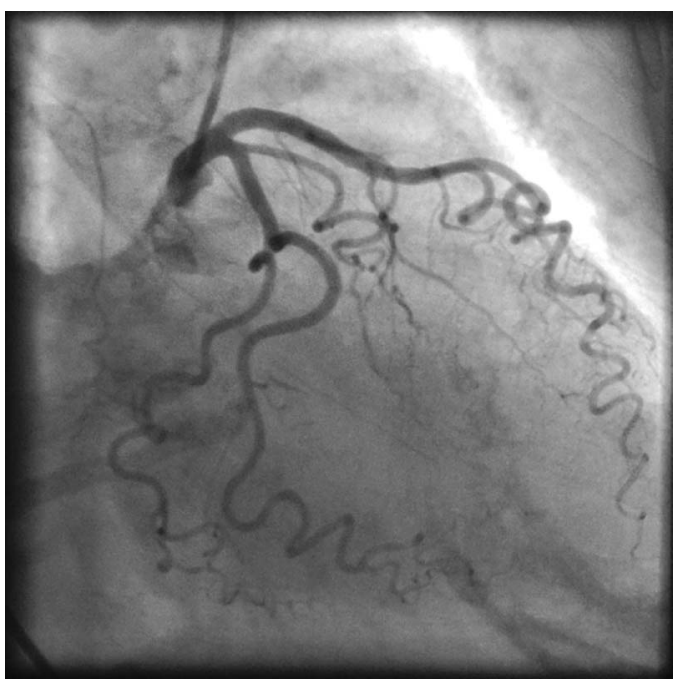

Figure 1 Right anterior oblique caudal view showing extremely tortuous left anterior descending and left circumflex coronary arteries.

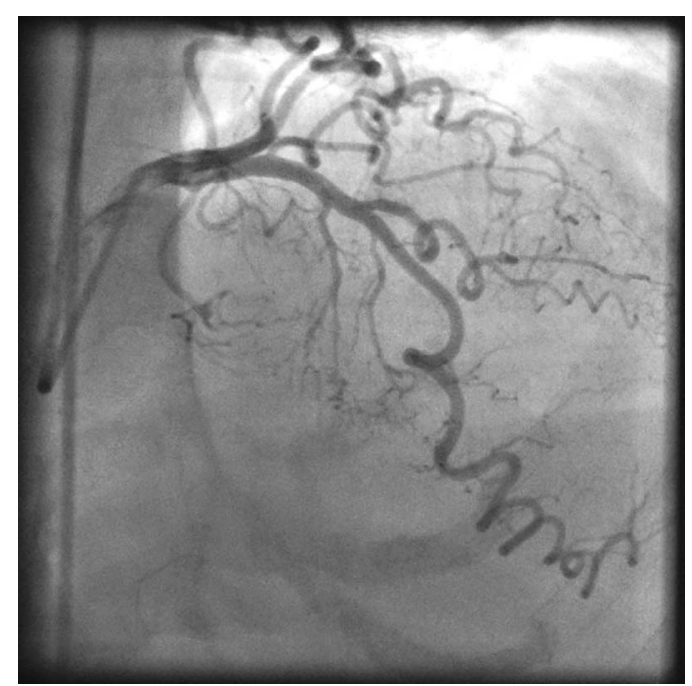

Figure 2 Anteroposterior cranial view showing extremely tortuous left anterior descending and left circumflex coronary arteries.

forces are opposed by a retractive force which maintains a stable length. ${ }^{2}$ In a study of patients with hypertension and aortic regurgitation, it was found that female sex and pressure overload are predictive of coronary artery tortuosity. In another study it was postulated that the determinants of coronary tortuosity were sex, age, left ventricular volume and muscle mass. ${ }^{3} 4$

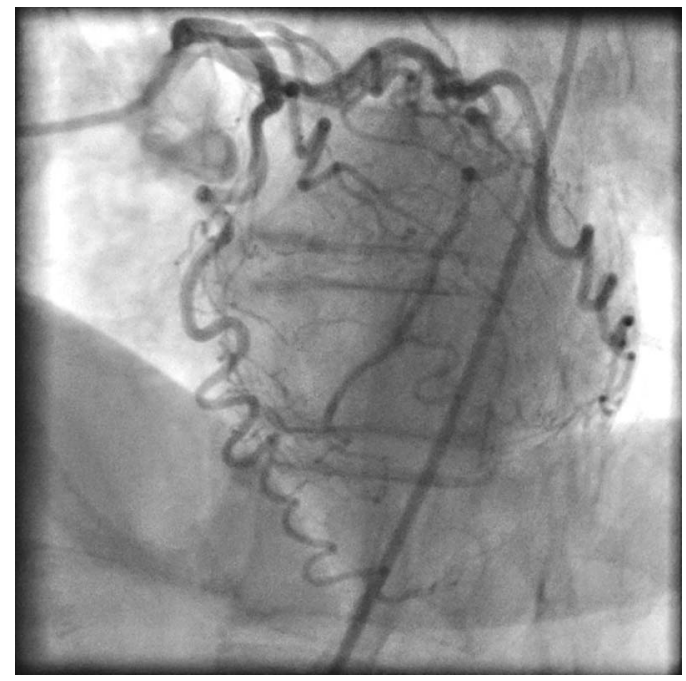

Figure 3 Left anterior oblique cranial view showing extremely tortuous left anterior descending and left circumflex coronary arteries. 


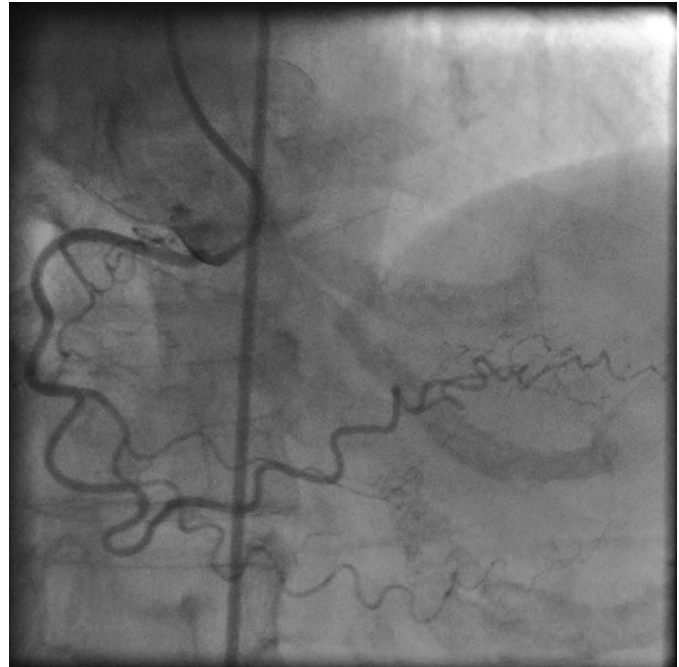

Figure 4 Left anterior oblique view showing extremely tortuous right coronary artery.

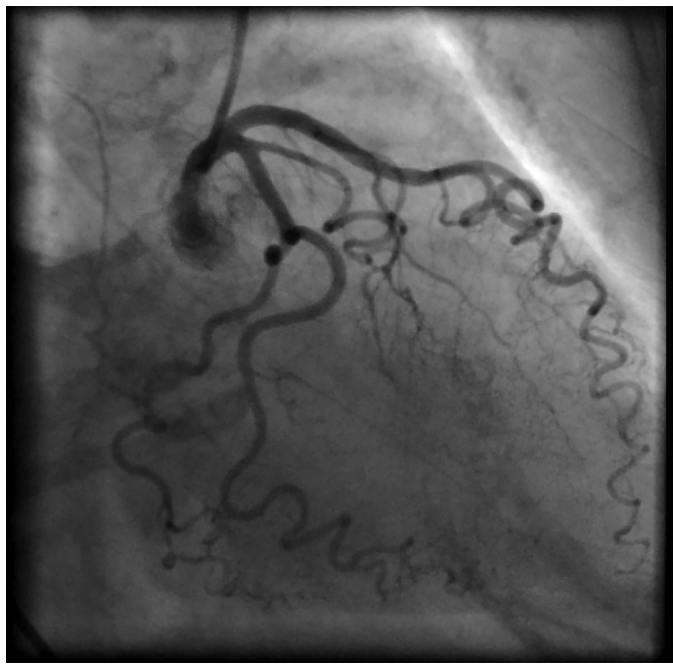

Video 1 RAO caudal view showing extremely tortuous Left anterior descending and Left circumflex coronary arteries.

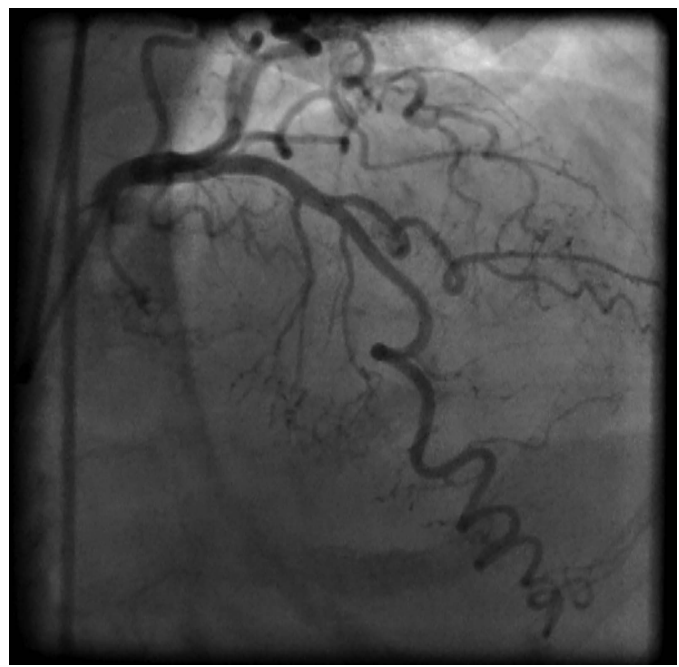

Video 2 AP cranial view showing extremely tortuous Left anterior descending and Left circumflex coronary arteries.

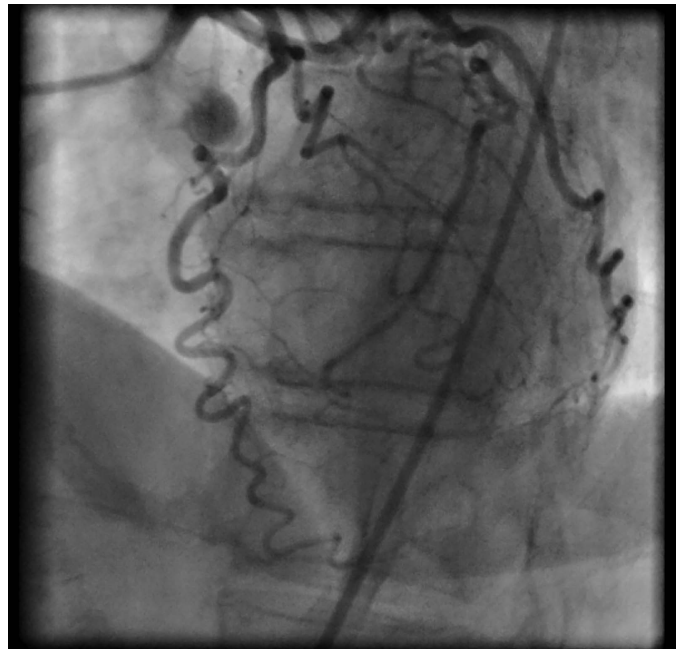

Video 3 LAO cranial view showing extremely tortuous Left anterior descending and Left circumflex coronary arteries.

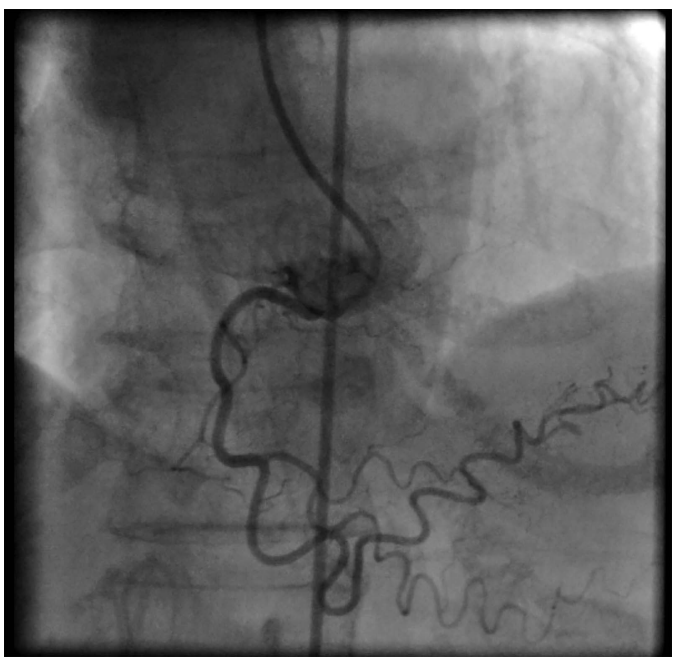

Video 4 LAO view showing extremely tortuous right coronary artery.

\section{Learning points}

- Extreme coronary artery tortuosity is an uncommon anomaly which is sometimes incidentally picked up during diagnostic angiograms which are performed for evaluation of atherosclerotic coronary artery disease.

- Most cases are usually asymptomatic and require no intervention if there is no coexistent atherosclerotic coronary artery disease.

- Performance of percutaneous interventions is a challenging task in cases with extreme tortuosity prior to the target atherosclerotic lesion with respect to the difficulty in manoeuvring the wires and stents across the tortuous segment.

Competing interests None.

Patient consent Obtained.

Provenance and peer review Not commissioned; externally peer reviewed. 


\section{REFERENCES}

1 Groves SS, Jain AC, Warden BE II, et al. Severe coronary tortuosity and the relationship to significant coronary artery disease. W V Med J 2009;105:14-17.

2 Dobrin PB, Schwarcz TH, Baker WH. Mechanisms of arterial and aneurysmal tortuosity. Surgery 1988;104:568-71.
3 Jakob M, Spasojevic D, Krogmann ON, et al. Tortuosity of coronary arteries in chronic pressure and volume overload. Cathet Cardiovasc Diagn 1996;38:25-31.

4 Zegers ES, Meursing BT, Zegers EB, et al. Coronary tortuosity: a long and winding road. Neth Heart J 2007;15:191-5.

Copyright 2014 BMJ Publishing Group. All rights reserved. For permission to reuse any of this content visit http://group.bmj.com/group/rights-licensing/permissions.

BMJ Case Report Fellows may re-use this article for personal use and teaching without any further permission.

Become a Fellow of BMJ Case Reports today and you can:

- Submit as many cases as you like

- Enjoy fast sympathetic peer review and rapid publication of accepted articles

- Access all the published articles

- Re-use any of the published material for personal use and teaching without further permission

For information on Institutional Fellowships contact consortiasales@bmjgroup.com

Visit casereports.bmj.com for more articles like this and to become a Fellow 